\title{
Latent Stem and Progenitor Cells in the Hippocampus Are Activated by Neural Excitation
}

\author{
Tara L. Walker, Amanda White, Debra M. Black, Robyn H. Wallace, Pankaj Sah, and Perry F. Bartlett \\ Queensland Brain Institute, The University of Queensland, Brisbane, Queensland 4072, Australia
}

The regulated production of neurons in the hippocampus throughout life underpins important brain functions such as learning and memory. Surprisingly, however, studies have so far failed to identify a resident hippocampal stem cell capable of providing the renewable source of these neurons. Here, we report that depolarizing levels of $\mathrm{KCl}$ produce a threefold increase in the number of neurospheres generated from the adult mouse hippocampus. Most interestingly, however, depolarizing levels of $\mathrm{KCl}$ led to the emergence of a small subpopulation of precursors (approximately eight per hippocampus) with the capacity to generate very large neurospheres $(>250 \mu \mathrm{m} \mathrm{in}$ diameter). Many of these contained cells that displayed the cardinal properties of stem cells: multipotentiality and self-renewal. In contrast, the same conditions led to the opposite effect in the other main neurogenic region of the brain, the subventricular zone, in which neurosphere numbers decreased by $\sim 40 \%$ in response to depolarizing levels of $\mathrm{KCl}$. Most importantly, we also show that the latent hippocampal progenitor population can be activated in vivo in response to prolonged neural activity found in status epilepticus. This work provides the first direct evidence of a latent precursor and stem cell population in the adult hippocampus, which is able to be activated by neural activity. Because the latent population is also demonstrated to reside in the aged animal, defining the precise mechanisms that underlie its activation may provide a means to combat the cognitive deficits associated with a decline in neurogenesis.

Key words: hippocampus; stem cell; precursor; activation; depolarization; potassium

\section{Introduction}

There are two primary neurogenic regions of the adult mammalian brain: the subventricular zone (SVZ) (Lois and AlvarezBuylla, 1993; Luskin, 1993) and the hippocampus (Altman and Das, 1965; Kuhn et al., 1996). Because large numbers of hippocampal neurons are generated throughout the life of an animal, such neurogenesis would be expected to be ultimately dependent on a resident or nearby stem cell population as it is in the SVZ (Reynolds and Weiss, 1992; Richards et al., 1992). However, although the stem cell in the SVZ has been identified (Rietze et al., 2001), the presence of a bona fide stem cell in the adult hippocampus remains controversial. Although some studies have indicated the presence of a stem cell in adult rodent hippocampus maintained long-term in a monolayer adherent culture in the presence of serum (Gage et al., 1995; Palmer et al., 1995, 1997), more recent studies using the neurosphere assay to identify precursors at the clonal level have so far identified only progenitor cells that have limited self-renewal capacity (Seaberg and van der Kooy, 2002; Bull and Bartlett, 2005). This raises the question of whether there is a quiescent latent population of stem cells in the

Received Jan. 25, 2008; revised March 19, 2008; accepted April 9, 2008.

This work was supported by a National Health and Medical Research Council program grant (P.F.B., P.S.). P.F.B. was supported by an Australian Research Council Federation Fellowship. We thank the staff at the University of Queensland School of Biomedical Sciences Animal Facility for maintaining and breeding the animals used in this study and Rowan Tweedale for editorial assistance.

Correspondence should be addressed to Perry F. Bartlett, Queensland Brain Institute, The University of Queensland, Brisbane, Queensland 4072, Australia. E-mail: p.bartlett@uq.edu.au.

DOI:10.1523/JNEUROSCI.0344-08.2008

Copyright $\odot 2008$ Society for Neuroscience $\quad 0270-6474 / 08 / 285240-08 \$ 15.00 / 0$ hippocampus and, more importantly, how this population might be regulated.

Neurogenesis in the subgranular cell layer of the dentate gyrus of the adult hippocampus has been shown to be influenced by environmental factors (Gould et al., 1999; van Praag et al., 1999), antidepressants (Santarelli et al., 2003), disease states (Nakatomi et al. 2002; Jin et al., 2004), and behavioral stimuli (Goldman and Nottebohm, 1983), and to be linked to learning and memory functions (Shors et al., 2001). The mechanism coupling neuronal production to external stimuli is thought to occur through synaptic activity (McEwen, 1994; van Praag et al., 1999; Brown et al., 2003; Ramirez-Amaya et al., 2006). Previous studies have shown that the application of depolarizing levels of extracellular $\mathrm{KCl}$, thereby mimicking the effects of stably increased activity in an active neural network, leads to an increase in neuronal production from adult hippocampal neural progenitor cells (Deisseroth et al., 2004). Because neurogenesis appears to be linked to levels of synaptic activity, we hypothesized that altered $\mathrm{KCl} \mathrm{levels} \mathrm{might}$ also regulate stem cell activity. Here, we show that there is a latent pool of neural stem cells in the adult hippocampus that can be activated by depolarizing levels of extracellular $\mathrm{KCl}$ in vitro. Moreover, we show that this latent precursor population can also be activated in vivo during pilocarpine-induced status epilepticus.

\section{Materials and Methods}

Primary neurosphere cultures. Adult (6-8 weeks of age, except where specifically stated) male C57BL/6 mice were killed by cervical dislocation, their brains were immediately removed, and the hippocampus or SVZ was dissected. The tissue was enzymatically digested with $0.1 \%$ trypsin- 
EDTA (Invitrogen, Carlsbad, CA) for $7 \mathrm{~min}$ at $37^{\circ} \mathrm{C}$, followed by a wash with $0.014 \% \mathrm{w} / \mathrm{v}$ trypsin inhibitor (type I-S from soybean; SigmaAldrich, St. Louis, MO) dissolved in HEPES-buffered minimum essential medium (HEM), which consisted of minimum essential medium (Invitrogen) supplemented with $16 \mathrm{~mm}$ HEPES (Sigma-Aldrich) and 100 $\mathrm{U} / \mathrm{ml}$ penicillin/streptomycin (Invitrogen). The tissue was centrifuged at $100 \mathrm{rcf}$ for $7 \mathrm{~min}$, after which the pellet was resuspended in $1 \mathrm{ml}$ of neurosphere growth medium, mechanically triturated until smooth, and then filtered through a $40 \mu \mathrm{m}$ cell sieve (Falcon; BD Biosciences Discovery Labware, Bedford, MA). The neurosphere growth medium consisted of mouse NeuroCult NSC Basal Medium plus mouse NeuroCult NSC Proliferation Supplements (Stem Cell Technologies, Vancouver, British Columbia, Canada) with $2 \%$ bovine serum albumin (Invitrogen) and 2 $\mu \mathrm{g} / \mathrm{ml}$ heparin (Sigma-Aldrich). The following growth factors were also included: $20 \mathrm{ng} / \mathrm{ml}$ purified mouse receptor-grade epidermal growth factor (EGF) (BD Biosciences, San Jose, CA) and $10 \mathrm{ng} / \mathrm{ml}$ recombinant bovine FGF-2 (Roche, Basel, Switzerland). After centrifugation at $100 \mathrm{rcf}$ for $7 \mathrm{~min}$, the cells were plated at a density of approximately one hippocampus or SVZ per 96-well plate (Falcon; BD Biosciences Discovery Labware) with $200 \mu \mathrm{l}$ of neurosphere medium per well. The neurosphere growth medium already contained $4.18 \mathrm{~mm} \mathrm{KCl}$. Therefore, for the depolarization experiments, additional $\mathrm{KCl}$ was added to give the appropriate final $\mathrm{KCl}$ concentration. Nicardipine (Sigma-Aldrich) was added to a final concentration of $10 \mu \mathrm{M}$. $\mathrm{BaCl}$ was used at a concentration of 1 $\mathrm{mm}, \mathrm{GABA}$ at $100 \mu \mathrm{M}$, and D-2-amino-5-phosphonopentanoate (D-AP5) at $30 \mu \mathrm{M}$. Primary hippocampal cells were incubated for $10 \mathrm{~d}$ and SVZ cells for $7 \mathrm{~d}$ in humidified $5 \% \mathrm{CO}_{2}$ to permit neurosphere formation. The primary neurospheres were then counted and collected for passaging or differentiation. Results of the neurosphere counts were expressed as mean \pm SE and statistical analysis was performed using a standard $t$ test (two-sample assuming equal variance).

To determine whether the $\mathrm{KCl}$ was activating a slowly dividing or nondividing population, $1 \mu \mathrm{M}$ cytosine arabinofuranoside (Ara-C) (Sigma-Aldrich) was added to primary dissociated hippocampal cells to kill any rapidly dividing cells. After $2 \mathrm{~d}$ at $37^{\circ} \mathrm{C}$, the Ara-C was removed by spinning the cells for $5 \mathrm{~min}$ and then washing with $10 \mathrm{ml}$ of complete medium. Cells were then replated in complete medium containing either control or $15 \mathrm{~mm} \mathrm{KCl}$ and incubated as described above.

To confirm that $\mathrm{KCl}$ was not simply enhancing the survival, the precursor cell experiments were repeated using Bax-deficient mice that lack programmed cell death in the hippocampus (Sun et al., 2004). Hippocampal tissue was dissected from Bax-deficient and wild-type littermate control animals and dissociated as described previously. Cells were then plated in complete medium containing either control or $15 \mathrm{mM} \mathrm{KCl}$ and incubated as described above.

For the limiting dilution experiment, primary cells were plated at reducing densities in 96-well plates with $200 \mu \mathrm{l}$ of complete medium containing EGF and bFGF-2 (basic FGF-2). Cell were plated at 3950, 1975, $988,494,247,123$, and 62 cells per well. After $10 \mathrm{~d}$ in vitro, the fraction of wells negative for neurosphere formation was quantified. These data were then log transformed and plotted against plating density. A linear regression was performed and a straight line fitted to the data.

Neurosphere differentiation. Neurospheres were plated onto poly-Dlysine-coated coverslips in NeuroCult NSC Basal Medium containing mouse NeuroCult NSC Proliferation Supplements and 2\% fetal calf serum without growth factors. The neurospheres were allowed to differentiate for $5 \mathrm{~d}$ in humidified $5 \% \mathrm{CO}_{2}$ until flattened and adherent. The differentiated neurospheres were then fixed with $4 \%$ paraformaldehyde in $0.1 \mathrm{~m}$ PBS at room temperature for $30 \mathrm{~min}$. After washing with PBS, they were stained for either the neuronal marker $\beta$ III-tubulin, the neuronal progenitor marker doublecortin (DCX), the astrocytic marker glial fibrillary acidic protein (GFAP), or the stem cell marker nestin, with a 4'-6'diamidino-2-phenylindole (DAPI) counterstain (see below).

Immunocytochemistry. The cells were incubated for $60 \mathrm{~min}$ at room temperature with blocking solution: $5 \%$ fetal bovine serum (SigmaAldrich) plus 5\% normal goat serum (Sigma-Aldrich) in 0.1 м PBS containing $0.1 \%$ Triton $\mathrm{X}-100$. The blocking solution was replaced with fresh solution containing mouse monoclonal $\beta$ III-tubulin antibody (1: 2000; Promega, Madison, WI) plus rabbit polyclonal GFAP antibody
(1:500; Dako North America, Carpinteria, CA), rabbit polyclonal DCX antibody (1:500; Millipore Bioscience Research Reagents, Cambridge, UK), or the mouse monoclonal nestin antibody (1:500; Millipore Bioscience Research Reagents) and incubated for $60 \mathrm{~min}$ at room temperature. The cells were then washed with PBS and incubated for $30 \mathrm{~min}$ at room temperature in blocking solution containing Alexa Fluor 568 antimouse antibody (1:1000; Invitrogen), Alexa Fluor 488 anti-rabbit antibody (1:1000; Invitrogen), and DAPI (1:5000; Sigma-Aldrich). After washing with PBS, the slides were coverslipped with fluorescence mounting medium (Dako North America) before viewing on a Carl Zeiss upright fluorescence microscope. Images were captured by a digital camera linked to a computer running Axioscope version 4 (Carl Zeiss, Jena, Germany).

Hippocampal neurosphere passaging. Hippocampal neurosphere cultures were initiated by removing $150 \mu \mathrm{l}$ of the medium from wells containing single neurospheres, and treating with $100 \mu \mathrm{l}$ of $0.1 \%$ trypsinEDTA for $2 \mathrm{~min}$ at room temperature, followed by washing with $100 \mu \mathrm{l}$ of trypsin inhibitor in HEM. The neurospheres were mechanically triturated until dissociated and replated in 24-well plates in $2 \mathrm{ml}$ of complete medium. Neurospheres were passaged every $10 \mathrm{~d}$ by removing the medium containing the neurospheres from the plates and centrifuging. The supernatant was then decanted, and the neurospheres were incubated in $1 \mathrm{ml}$ of $0.1 \%$ trypsin-EDTA for $2 \mathrm{~min}$ at room temperature. After the addition of an equal volume of trypsin inhibitor, the neurospheres were centrifuged at $100 \mathrm{rcf}$ for $5 \mathrm{~min}$ and the supernatant was removed. Cells were mechanically triturated in $500 \mu \mathrm{l}$ of complete medium and trypan blue staining was used to evaluate the number of cells, both viable and total number, on a hemocytometer. The passaged cells were then replated with complete medium at a density of $1 \times 10^{4} \mathrm{cells} / \mathrm{cm}^{2}$ in tissue culture flasks (Nalge Nunc International, Rochester, NY) or tissue culture plates (Falcon; BD Biosciences Discovery Labware) as appropriate.

Fluorescence-activated cell sorting. Mice in which green fluorescent protein (GFP) is driven by the DCX promoter (DCX-GFP) were used for the separation of DCX ${ }^{+}$cells. Hippocampal tissue from adult DCX-GFP mice (Gensat BAC Transgenic Project, The Rockefeller University, New York, NY) was dissected and processed as described above. DCX-GFP ${ }^{+}$ and DCX-GFP ${ }^{-}$cells were separated by fluorescence-activated cell sorting (FACS) using a FACSVantage cell sorter (BD Biosciences) as previously described (Walker et al., 2007). A wild-type littermate control was used to determine background fluorescence levels. $\mathrm{KCl}$ was added to $\mathrm{DCX}^{+}$and DCX ${ }^{-}$cells at a final concentration of $15 \mathrm{~mm}$, and the number of neurospheres was counted after $10 \mathrm{~d}$.

Pilocarpine-induced seizures. Seizures were induced in 6- to 8-week-old C57BL/6 male mice by the administration of pilocarpine, a muscarinic cholinergic agonist. Thirty minutes before pilocarpine administration, the mice were injected with $2.5 \mathrm{mg} / \mathrm{kg}$ of the cholinergic antagonist scopolamine methyl nitrate (Sigma-Aldrich) to reduce peripheral cholinergic effects. They then received intraperitoneal injections of $350 \mathrm{mg} / \mathrm{kg}$ pilocarpine hydrochloride (Sigma-Aldrich). Seizures were observed in $70 \%$ of the mice and of these $35 \%$ entered into status epilepticus $78 \pm 43$ min after the injection of pilocarpine. Generalized tonic clonic seizures were observed in the other $35 \%$ of mice. Seizures were stopped $2 \mathrm{~h}$ after onset, with an intraperitoneal injection of $5 \mathrm{mg} / \mathrm{kg}$ diazepam (Parnell Laboratories, Sydney, Australia). Mice that did not enter status epilepticus also received diazepam and were used as controls. Mice were killed after $2 \mathrm{~d}$ and neurosphere assays performed.

BDNF neutralization and BDNF-deficient mice. To test whether the depolarization-induced activation of precursors was attributable to release of brain-derived neurotrophic factor (BDNF), anti-human BDNF neutralizing antibody ( $20 \mu \mathrm{g} / \mathrm{ml}$; Promega) was added to primary hippocampal cells in the presence of $15 \mathrm{~mm} \mathrm{KCl}$. BDNF heterozygous knockout $\left(\mathrm{BDNF}^{+/-}\right)$(Korte et al., 1995) and wild-type littermate control $\left(\mathrm{BDNF}^{+/+}\right)$mice were used in the hippocampal KCl-depolarized neurosphere assay (as described above) to determine the effect of BDNF.

\section{Results}

Depolarization activates hippocampal stem cells in vitro To investigate whether depolarizing levels of $\mathrm{KCl}$ are able to activate hippocampal stem cells, $15 \mathrm{~mm} \mathrm{KCl}$ was used to depolarize 
cultures of cells freshly isolated from an adult mouse hippocampus, and the number of neurospheres generated after $10 \mathrm{~d}$ was assessed using a previously described in vitro assay (Bull and Bartlett, 2005). Surprisingly, we found there was a threefold increase in the number of neurospheres generated in the presence of high extracellular $\mathrm{KCl}(320.3 \pm 36.5 \%$ of control; $p<$ $0.001 ; n=6)$ compared with cultures plated in control $(4 \mathrm{mM}) \mathrm{KCl}$ concentrations (Fig. $1 A$ ) or in $20 \mathrm{~mm} \mathrm{NaCl}(106.8 \pm$ $10.0 \%$ of control; $n=2$ ). A dose-response assay revealed that levels of $\mathrm{KCl}$ as low as 10 $\mathrm{mm}$ and as high as $30 \mathrm{~mm}$ could also elicit a significant increase in the number of neurospheres generated (data not shown). Raising extracellular $\mathrm{KCl}$ is expected to simply depolarize cells, and, in confirmation of this, when a depolarizing concentration of $\mathrm{BaCl}(1 \mathrm{~mm})$ was added to the cultures there was a similar increase in neurosphere numbers $(227.9 \pm 8.4 \% ; p<$ $0.001 ; n=4)($ Fig. $1 \mathrm{~A})$.

Interestingly, application of high extracellular $\mathrm{KCl}$ led to the emergence of a subpopulation $(\sim 5 \%)$ of very large neurospheres, $250-550 \mu \mathrm{m}$ in diameter (Fig. $1 B, C)$. This equates to approximately eight (8.4 $\pm 0.8 ; n=16$ experiments) of these large $\mathrm{KCl}$-stimulated neurospheres per hippocampus. Depolarization with $\mathrm{BaCl}$ gave a similar number of large neurospheres. These neurospheres were even larger than those cultured from precursors isolated from the neurogenic region of the SVZ, an area in which neurosphere size reflects the presence of a stem cell phenotype (Bull and Bartlett, 2005).

We also examined whether there was a similar latent population in the other major neurogenic region of the brain, the SVZ. In contrast to the hippocampus, we found the opposite effect in the SVZ: neurosphere numbers decreased by $\sim 40 \%$ in response to depolarizing levels of $\mathrm{KCl}$ (Fig. $1 A)(62.7 \pm 3.5 \%$; $p<0.001$; $n=4$ ). As has been reported previously (Bull and Bartlett, 2005), neurospheres grown from the SVZ consistently produced large $(>100 \mu \mathrm{m})$ neurospheres, some of which could be passaged and, after differentiation, gave rise to neurons. However, there was no shift in neurosphere size or increase in neuronal numbers in neurospheres cultured in the presence of $\mathrm{KCl}$.

To determine whether cells in these large hippocampal neurospheres reflected similar stem cell characteristics, individual neurospheres of different sizes were isolated, dissociated, and then replated into medium containing control levels of $\mathrm{KCl}$. To confirm the findings of previous studies, we also attempted to passage neurospheres from the unstimulated hippocampus. We found that $\sim 36 \%$ of the selected single large neurospheres ( 23 of 64 ) could be expanded for at least 10 passages (Fig. 1D), whereas none of the neurospheres ( 0 of 113) originally generated in the absence of high $\mathrm{KCl}$ could be passaged more than twice, regardless of whether $15 \mathrm{~mm} \mathrm{KCl}$ was added to the medium at the time of passaging. Similarly, the small neurospheres generated under depolarizing conditions could not be passaged (0 of 132). Furthermore, after differentiation, primary control (Fig. $2 A$ ), as well
B

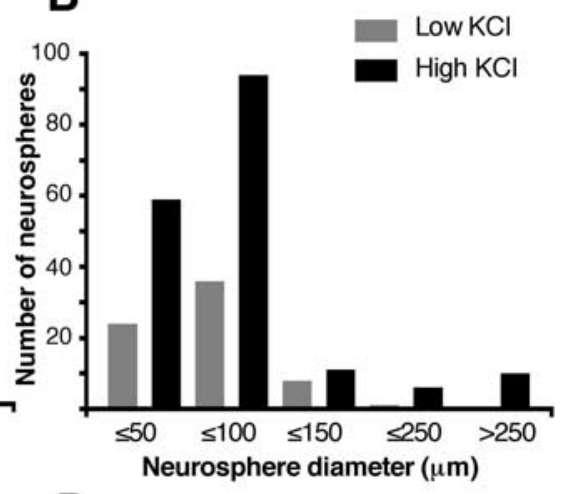

High $\mathrm{KCl}$

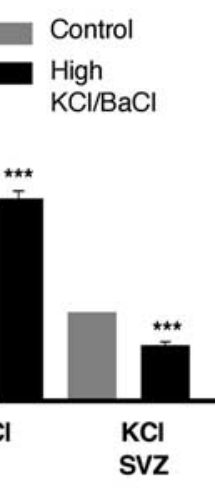

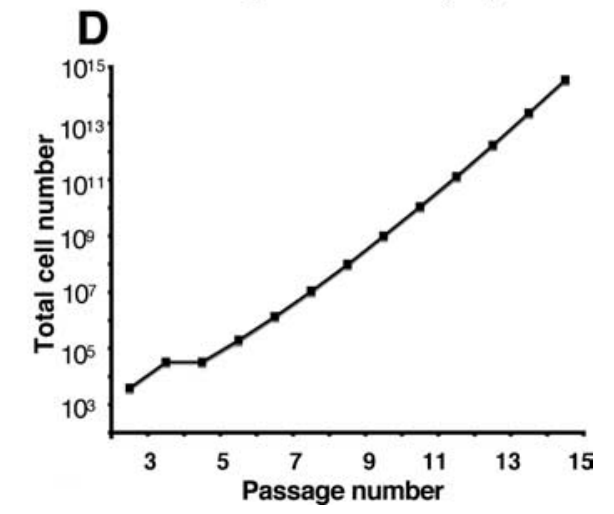

Figure 1. A, Depolarization activates hippocampal stem cells in vitro. Depolarization using $15 \mathrm{~mm} \mathrm{KCl}$ or $1 \mathrm{~mm} \mathrm{BaCl} \mathrm{significantly}$ increased the number of neurospheres generated from the adult mouse hippocampus (mean \pm SEM; $n=6$ experiments; which compares an average neurosphere to one of the large neurospheres cultured in high $\mathrm{KCl}$. $\boldsymbol{D}$, Single large $\mathrm{KCl}$-derived neurospheres could be continually expanded in vitro for $>13$ passages. Scale bar, $100 \mu \mathrm{m}$.

as the small primary neurospheres generated in $\mathrm{KCl}$-activated conditions, contained virtually no neurons $(<0.001 \beta \mathrm{III}-$ tubulin-positive cells per neurosphere; $n=20)$. In contrast, however, large primary $\mathrm{KCl}$-activated neurospheres generated a small number of neurons initially (average of $3.4 \pm 1.1 \beta$ III-tubulinpositive cells per neurosphere; $n=18$ neurospheres), and a large number $(26.9 \pm 2.1 \% \beta$ III-tubulin-positive cells per neurosphere; $n=15$ neurospheres) after several passages (Fig. $2 B$ ). Additional characterization of these $\mathrm{KCl}$-induced passaged neurospheres revealed that, although a large number of cells remained undifferentiated, as shown by their expression of the precursor marker nestin (Fig. 2C), cells expressing the neuronal progenitor marker DCX were clearly present (Fig. 2D). Thus, depolarization activated a latent population with the stem cell characteristics of self-renewal and multipotentiality and, most importantly, the capacity to produce large numbers of neurons.

In the present study, although we cultured tissue from the entire hippocampus, we were never able to isolate a stem cell under non-depolarizing conditions. We further confirmed our results were not attributable to dissection technique by subregional dissection of the hippocampus, which revealed that the major increase in depolarization-induced precursor number occurred in the dentate gyrus $(730.0 \pm 350.0 \%$ of control) and that this region contained a stem cell population (supplemental Fig. 1, available at www.jneurosci.org as supplemental material). Interestingly, precursor activation was also observed in the CA1/CA3 region after depolarization, although to a lesser extent $(406.3 \pm$ 

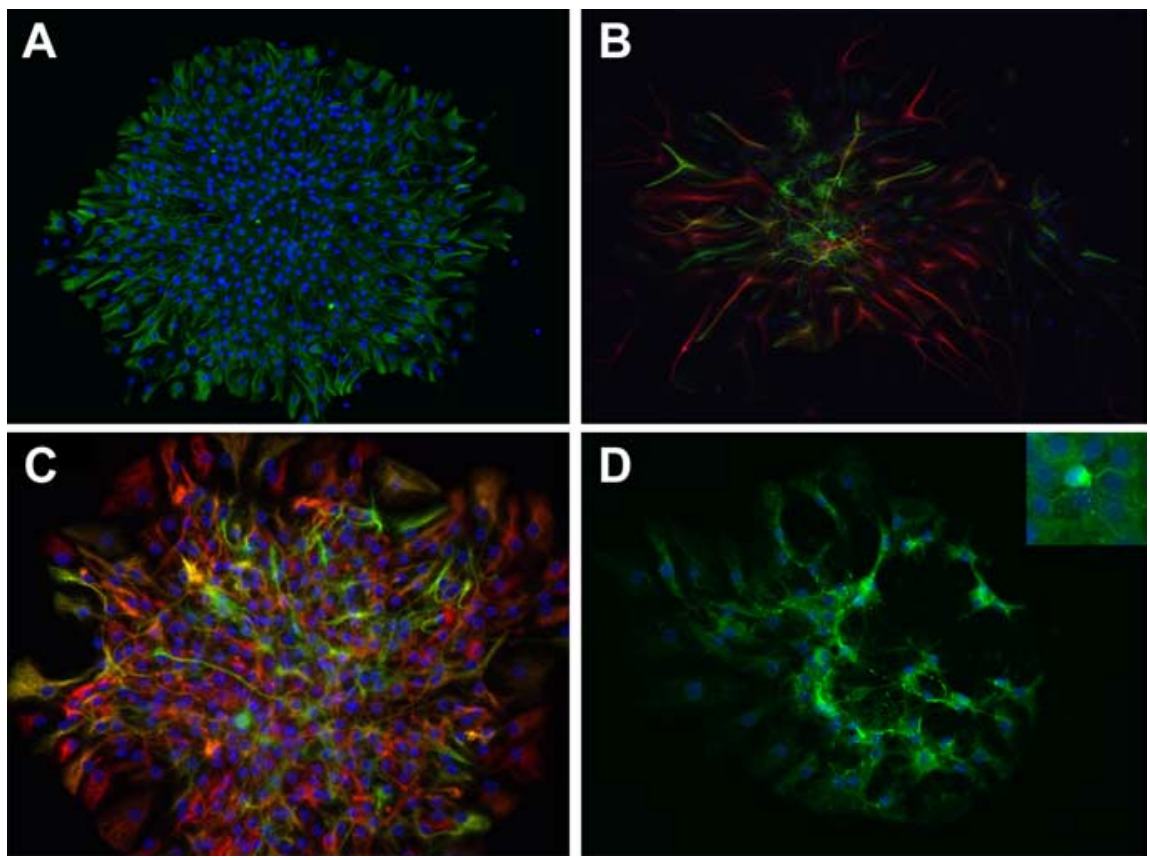

Figure 2. Effects of $\mathrm{KCl}$ of differentiation of neurospheres. $A$, The primary neurospheres in low $\mathrm{KCl}$ conditions contained only astrocytes after differentiation. $\boldsymbol{B}$, However, after repeated passaging in vitro, the neurospheres from the high $\mathrm{KCl}$-stimulated cultures contained a large number of $\beta$ III-tubulin-positive neurons (red) and GFAP-positive astrocytes (green). C, Passaged neurospheres were also stained for nestin (red), a marker for stem cells, and GFAP (green) and (D) doublecortin (green), an early neuronal marker. Cell nuclei are counterstained with DAPI (blue). Magnification: $\boldsymbol{A}-\boldsymbol{D}, 20 \times ; \boldsymbol{D}$, inset, $40 \times$.

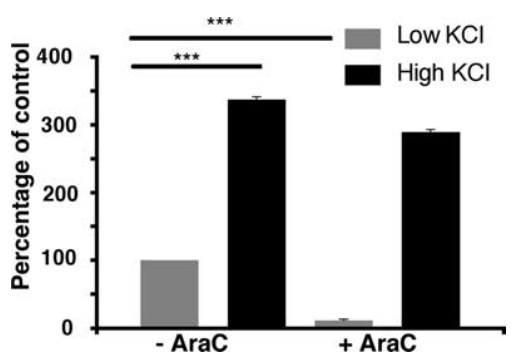

Figure 3. The KCl-activatable cells are a slowly dividing or nondividing population. Treatment with $1 \mu \mathrm{m}$ Ara-C for $2 \mathrm{~d}$ significantly reduced the number of hippocampal neurospheres generated under low $\mathrm{KCl}$ conditions. However, when cultures were grown in depolarizing levels of $\mathrm{KCl}$, Ara-C treatment had no significant effect on neurosphere number, indicating that the $\mathrm{KCl}$-activatable population is slowly dividing (mean $\pm \mathrm{SEM} ; n=2$ experiments; ${ }^{* *} p<$ 0.001).

$182.7 \%$ of control). This, however, was not completely unexpected because it has previously been reported that neuronal replacement occurs in this region after stroke (Bendel et al., 2005), indicating the presence of the latent precursor population in this area.

To determine whether the population of cells responding to depolarization in the hippocampus is a normally slowly dividing population, freshly isolated hippocampal cells were treated with the antimitotic agent Ara-C for $2 \mathrm{~d}$ in vitro to kill any rapidly dividing cells. This treatment had little effect on the $\mathrm{KCl}$ activated population of cells but markedly depleted the number of neurospheres generated under control conditions (Fig. 3). Given that depolarization is known to delay apoptotic cell death (Iacovitti et al., 1999), it was possible that the addition of $\mathrm{KCl}$ simply enhanced survival of the precursor cell population. To determine whether $\mathrm{KCl}$ was truly activating a latent population, rather than merely keeping the hippocampal precursors alive, we repeated our experiment using Bax knockout mice, which lack programmed cell death in the hippocampus (Sun et al., 2004). In these animals, we still observed a significant increase in precursor activation after depolarization $(198.8 \pm 14.7 \%$ increase in the presence of $15 \mathrm{~mm} \mathrm{KCl} ; n=$ 4 ), demonstrating that the response is not simply attributable to increased cell survival. More importantly, a similar number of large stem cell-derived neurospheres were only generated from Bax knock-out mice in the presence of $\mathrm{KCl}$.

Because application of $\mathrm{KCl}$ is expected to depolarize cells, it is possible that the coupling of $\mathrm{KCl}$ application and precursor cell activation results from the opening of voltage-dependent ion channels. L-type $\mathrm{Ca}^{2+}$ channels are known to modulate activity-dependent processes in neural cells (Dolmetsch et al., 2001; Deisseroth et al., 2004). We therefore tested whether the depolarization-induced activation of hippocampal precursors required activation of an L-type $\mathrm{Ca}^{2+}$ channel. In the presence of the antagonist nicardipine, the excitation-induced activation of neurosphere-forming cells in the hippocampus under depolarizing conditions was almost completely blocked (Fig. 4) (7.8 $\pm 3.8 \%$ of control; $p<0.001 ; n=3)$. However, again, no such effect was observed in the case of SVZ neurospheres in either the presence or absence of $\mathrm{KCl}$ (Fig. 4). It is possible that $\mathrm{KCl}$-induced depolarization leads to the release of glutamate from resident cells and activation of NMDA receptors (Deisseroth et al., 2004). However, there was no evidence of NMDA receptor involvement, because application of the specific antagonist D-AP5 caused no significant change in the number of hippocampal neurospheres $(84.0 \pm 10.0 \%$ of $\mathrm{KCl}$ alone; $n=2$ ). This result was somewhat surprising, given the previous reports of NMDA receptor involvement in the regulation of neuronal differentiation in response to depolarization (Deisseroth et al., 2004). However, consistent with this result, application of $100 \mu \mathrm{M}$ glutamate also produced no increase in neurosphere formation.

Limiting dilution analysis revealed that the effect of depolarization appeared to be a direct effect on the precursor (Fig. 5), because there was no change in the slope even at cell densities as low as 60 cells per well. In addition, the frequency of large neurospheres was not influenced by cell density, supporting the clonality of the response.

We recently showed that, in addition to newly generated neurons, the hippocampal $\mathrm{DCX}^{+}$population contains a significantly higher precursor frequency than that found in the DCX ${ }^{-}$population (Walker et al., 2007). To further characterize this latent population, we sorted freshly isolated hippocampal cells on the basis of DCX expression and incubated the sorted cells in medium containing control levels or $15 \mathrm{~mm} \mathrm{KCl}$. Our results revealed, however, that it is the $\mathrm{DCX}^{-}$population that is responsive to depolarization when treated with $\mathrm{KCl}$ (Fig. 6) (325.9 $\pm 73.3 \%$ of control; $p<0.01 ; n=5$ ), consistent with this population being more stem cell-like. Although the $\mathrm{DCX}^{+}$population had an overall higher frequency of neurosphere-forming cells, no effect 


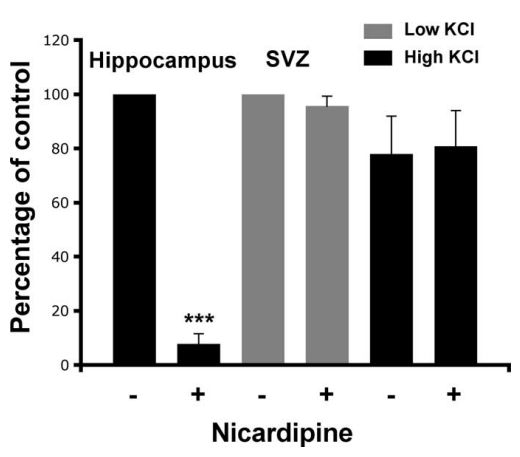

Figure 4. Depolarization-induced activation requires activation of an $\mathrm{L}-$ type $\mathrm{Ca}^{2+}$ channel. In the presence of depolarizing KCl levels, the L-type $\mathrm{Ca}^{2+}$ channel antagonist nicardipine (10 $\mu \mathrm{M}$ ) significantly reduced the formation of hippocampal neurospheres (mean $\pm \mathrm{SEM} ; n=3$; $\left.{ }^{* * *} p<0.001\right)$. In contrast, nicardipine had no effect on the formation of neurospheres from the SVZ in either the presence or absence of $\mathrm{KCl}(n=3)$.

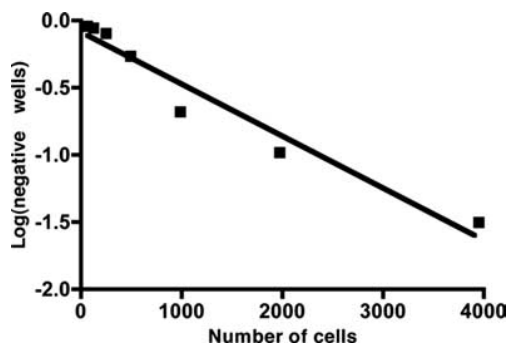

Figure 5. Limiting dilution neuropshere assay of primary hippocampal tissue plated in the presence of depolarizing levels of $\mathrm{KCl}$. No change was observed in the slope of the line even at cell densities as low as 60 cells per well, indicating that depolarization was exerting a direct effect on the precursor with neurosphere-forming frequency independent of cell plating density.

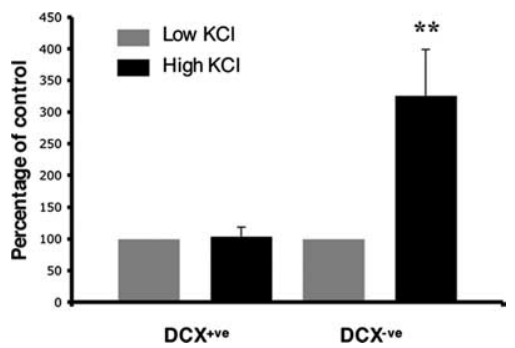

Figure 6. The $D C X^{-}$population is responsive to $\mathrm{KCl}$ depolarization. Cells from DCX-GFP transgenic mice were FACS sorted into $D C X^{+}$and $D C X^{-}$populations based on GFP expression and plated in either the presence or absence of $15 \mathrm{~mm} \mathrm{KCl}$. Analysis of resulting neurosphere numbers revealed that it is the $\mathrm{DCX}{ }^{-}$population that is responsive to depolarization (mean \pm SEM, $326 \pm 73 \%$ of control; $\left.{ }^{* *} p<0.01 ; n=5\right)$. The $D C X^{+}$population had an overall higher frequency of neurosphere-forming cells. However, no effect of $\mathrm{KCl}$ depolarization was observed (mean \pm SEM, $104 \pm 14.6 \%$ of control; $n=5$ ).

of $\mathrm{KCl}$ depolarization was observed $(104.0 \pm 14.6 \%$ of control; $n=5)$.

\section{The hippocampal progenitor population is activated in vivo} after seizure

Based on the above lines of evidence, we next investigated whether the latent hippocampal population identified in vitro could also be activated by neural activity in vivo using the pilocarpine-induced seizure model. We found that mice that experienced status epilepticus for at least $2 \mathrm{~h}$ and were studied after $2 \mathrm{~d}$ had a significant increase in the number of hippocampal neurospheres compared with control mice, similar to the effect
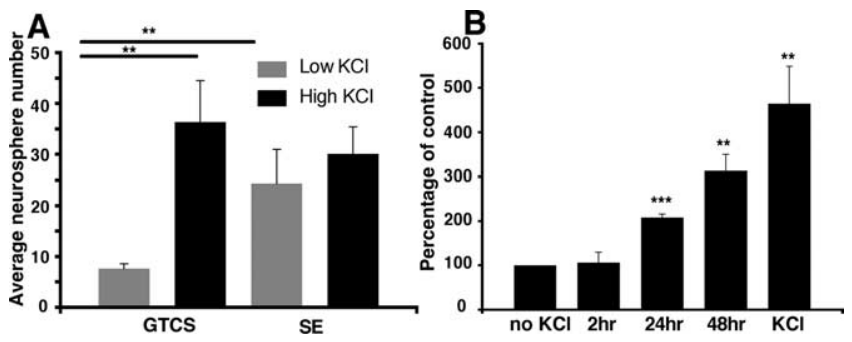

Figure 7. The hippocampal precursor population is activated in vivo after seizure. $A$, Similar to results obtained in control mice, the number of hippocampal neurospheres generated from those suffering sporadic seizures (GTCS) was low and could be significantly increased by the addition of $\mathrm{KCl}$ in vitro. However, the number of neurospheres generated from mice that underwent status epilepticus (SE) was greatly increased, and no additional increase was seen in the presence of $\mathrm{KCl}$ (mean \pm SEM; GTCS, $n=5 ; \mathrm{SE}, n=7$; ${ }^{* *} p<0.01$ ). $\boldsymbol{B}$, It takes at least $24 \mathrm{~h}$ for the $\mathrm{KCl}$-induced depolarization to activate the hippocampal precursor cells $\left({ }^{* *} p<0.01\right.$, $\left.{ }^{* * *} p<0.001 ; n=3\right)$.

observed in the KCl-stimulated cultures (Fig. 7A) $(9.8 \pm 1.7$ vs $21.0 \pm 6.7$ neurospheres). In contrast, mice that suffered only sporadic generalized tonic clonic seizures (GTCS) (up to 12 seizures observed in one mouse) showed no such increase (7.6 \pm 1.9 neurospheres), suggesting that prolonged activation is required for an effect to be observed. Consistent with the idea that status epilepticus activated the same population as $\mathrm{KCl}$ was the finding that $\mathrm{KCl}$-induced depolarization in vitro resulted in only a small increase in neurosphere number in the status epilepticus group, whereas there was a substantial increase in neurosphere number seen in the other conditions (no seizure, $816 \pm 222.6 \%$; GTCS, $709.6 \pm 279.3 \%$; status epilepticus, $151.8 \pm 16.9 \%$ of no $\mathrm{KCl}$ control). Interestingly, however, status epilepticus alone was not sufficient to activate the cells that resulted in the small population of large neurospheres observed after $\mathrm{KCl}$ depolarization. Based on this observation, we next examined whether prolonged excitation was also a requirement for activation in vitro, and found that at least $24 \mathrm{~h}$ exposure to high levels of $\mathrm{KCl}$ was required to produce a significant effect (Fig. 7B).

The precursor population is also activated in the aged hippocampus but not in the neonate

Paradoxically, it has been shown previously that the early postnatal hippocampus contains a large number of both precursors and multipotent stem cells (Seaberg and van der Kooy, 2002). We found that the number of postnatal day 2 (P2), P7, and P15 neurospheres, unlike in the adult, could not be significantly increased after depolarization (Fig. 8A) (P2, $121.0 \pm 28.0 \%$; P7, $131.9 \pm 11.2 \% ; \mathrm{P} 15,184.7 \pm 41.1 \%$ of control). Neonatal seizures have been reported to modulate neurogenesis at different time points, with downregulation after 8 and $14 \mathrm{~d}$ and upregulation after $49 \mathrm{~d}$ (Xiu-Yu et al., 2007). The fact that we see no activation of the precursor population after $\mathrm{KCl}$ treatment at postnatal day 2 or 7 may be attributable to the already enormous numbers of precursors (and stem cells) present in the neonatal hippocampus $(\sim 8000$ neurospheres were generated per P2 mouse hippocampus). It is only in the adult animal, in which the majority of this population has become latent, that we can observe a significant effect. The increase in neurogenesis observed after seizures in neonatal hippocampus may also be attributable to other factors, such as an increase in neuronal differentiation from existing precursors.

Our finding that a latent stem cell population resides in the hippocampus suggests that this may be able to be activated even in the aged animal. Using the neurosphere assay, we tested the 

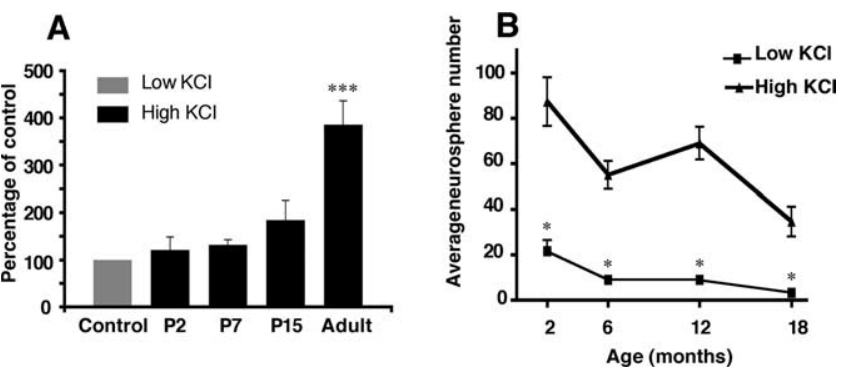

Figure 8. The precursor population is also activated in the aged but not the neonatal hippocampus. $A$, No significant increase was observed under depolarizing conditions in the $\mathrm{P} 2, \mathrm{P7}$, or P15 hippocampus. ${ }^{* * *} p<0.001$. $B$, Although the total number of neurospheres per hippocampus decreased with age, the percentage activation compared with age-matched controls increased, with the oldest animals tested (18 months) having a $>12$-fold increase in neurosphere number in the presence of $15 \mathrm{~mm} \mathrm{KCl}$ (mean \pm SEM; $n \geq 3 ;{ }^{*} p<0.05$ ).
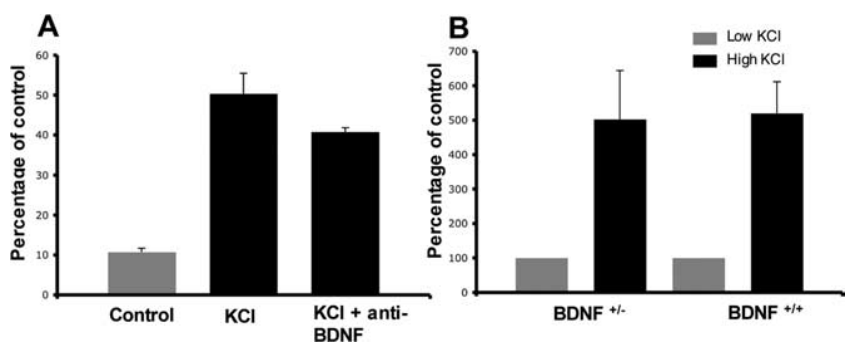

Figure 9. Hippocampal precursor activation is not occurring in response to BDNF release. $\boldsymbol{A}$ Addition of an anti-human BDNF neutralizing antibody was not able to block the depolarization-induced activation (mean \pm SEM; $n=6$ ). $\boldsymbol{B}$, No significant difference was observed in the depolarization-induced precursor activation between BDNF heterozygous knock-out and wild-type littermate control mice (mean \pm SEM; $n=6$ ).

activation of the latent precursor population with increasing age. We found that, although the number of neurosphere-forming cells in the hippocampus declined with age, a result that parallels the reported decline in neurogenesis, there was, in fact, a concomitant rise in the percentage of precursors that could be stimulated by depolarization with increasing age ( 2 months, $543.3 \pm$ $154.4 \%$; 6 months, $679.0 \pm 202.4 \%$; 12 months, $816.7 \pm 171.7$; 18 months, $1274.3 \pm 232.5 \%$ of control) (Fig. $8 B$ ). The oldest animals tested (18 months) had a $>12$-fold increase in the number of neurospheres generated in $\mathrm{KCl}$-stimulated compared with control cultures. However, in contrast to the younger animals, no large neurospheres were observed, and none of the neurospheres was passageable.

\section{Hippocampal precursor activation is not occurring in response to $\mathrm{BDNF}$ release}

We previously showed BDNF to have proneurogenic actions in both the SVZ (Young et al., 2007) and hippocampus (Bull and Bartlett, 2005). In addition, BDNF is released by hippocampal neuronal populations after seizures (Ballarin et al., 1991; Ernfors et al., 1991; Isackson et al., 1991; Dugich-Djordjevic et al., 1992). Our results show that, when added to primary hippocampal cultures in the presence of $15 \mathrm{~mm} \mathrm{KCl}$, anti-human BDNF neutralizing antibody was not able to block the depolarization-induced activation (Fig. 9A) (control, $10.6 \pm 1.0 ; \mathrm{KCl}, 50.3 \pm 5.1 ; \mathrm{KCl}$ plus anti-BDNF antibody, $40.8 \pm 1.0$ neurospheres per well; $n=$ 6). In further support of this, no difference was observed in the depolarization-induced precursor activation between BDNF heterozygous knock-out and wild-type littermate control mice (Fig.
9B) $\left(\mathrm{BDNF}^{+/-}, 502.6 \pm 141.0 \% \mathrm{vs} \mathrm{BDNF}^{+/+}, 519.5 \pm 91.7 \%\right.$ of no $\mathrm{KCl}$ control; $n=6$ ).

\section{Discussion}

This study provides evidence for the existence of a large latent precursor population in the hippocampus, some of which have stem cell properties. Most importantly, we also show that these precursors have properties significantly different from the better studied and characterized SVZ precursors in that they are regulated by neural activity. Our data suggest that in vitro application of $\mathrm{KCl}$ to primary hippocampal cultures leads to activation of a large pool of latent precursor cells, a small number of which are stem cells based on their ability to proliferate and differentiate into neurons. It is unlikely that $\mathrm{KCl}$ and the accompanying depolarization is simply supporting survival of precursors because depolarization in vitro was able to increase neurosphere numbers in Bax-deficient mice (Sun et al., 2004) in which apoptotic cell death is greatly reduced. More importantly, no large stem cellderived neurospheres were generated from the Bax-deficient animals under control $\mathrm{KCl}$ conditions.

The effect of $\mathrm{KCl}$ was also blocked by the specific L-type $\mathrm{Ca}^{2+}$ channel antagonist, nicardipine, indicating that activation of the latent population is initiated by opening of L-type $\mathrm{Ca}^{2+}$ channels. It was notable that, even in the absence of depolarizing levels of $\mathrm{KCl}$, a significant number of precursors were inhibited by nicardipine, suggesting that there is a steady-state activation of the system at basal levels. Prolonged neural activity in vivo initiated by pilocarpine-induced seizures also activated this latent population, indicating that the resultant depolarization is the likely mechanism for this action. Together, these results suggest a new mechanism for how neurogenesis in the adult hippocampus could be regulated.

Precisely how neural activity stimulates the latent precursor population in situ is not clear. The $\mathrm{K}^{+}$efflux that accompanies neural activity may simply depolarize local cells and/or release neural factors that initiate precursor activity. This factor is unlikely to be glutamate or GABA because their application resulted in only a small increase in progenitor number with no large neurospheres recorded. Consistent with this explanation, we found that medium conditioned with $\mathrm{KCl}$-depolarized primary hippocampal cells, but from which the $\mathrm{KCl}$ is subsequently removed, can also activate precursor activity (data not shown). It is well known that seizures lead to a marked but transient increase in BDNF mRNA levels in hippocampal neuronal populations (Ballarin et al., 1991; Ernfors et al., 1991; Isackson et al., 1991; Dugich-Djordjevic et al., 1992). We also previously demonstrated that BDNF is essential for the production of neurons from hippocampal progenitor cells (Bull and Bartlett, 2005). However, BDNF is unlikely to be responsible for the specific hippocampal precursor cell activation we observe, because BDNF has recently been shown to have a similar proneurogenic effect on precursor cells from the postnatal SVZ (Young et al., 2007). Moreover, neither neutralization of exogenous BDNF with an anti-BDNF antibody nor the use of BDNF heterozygous knock-out animals is able to block the depolarization-induced activation, indicating that BDNF is not involved in this process. Recent studies have shown that release of Wnt3a, either by activity-dependent synaptic release from adult hippocampal neurons (Chen et al., 2006) or through its secretion by hippocampal astrocytes (Lie et al., 2005), increases adult hippocampal neurogenesis, suggesting that Wnt 3 a could be involved.

Our findings also have implications for our understanding of the mechanisms regulating progenitor activity in disease states in 
which activity-dependent proliferation in the hippocampus results in an acute increase in local excitation (Liu et al., 1998; Gould et al., 2000; Arvidsson et al., 2001). We chose to investigate an epilepsy model, because status epilepticus has previously been reported to lead to a prolonged increase in synaptic activity, resulting in depolarization throughout the brain (Sloviter, 1983) and an increase in neurogenesis in the dentate gyrus (Parent et al., 1997). We suggest that the activation of the hippocampal progenitors we observe after seizure in vivo is occurring via a similar mechanism to that initiated by $\mathrm{KCl}$ depolarization in vitro. Our finding that status epilepticus was required for at least $2 \mathrm{~h}$ to cause an increase in the number of hippocampal neurospheres suggests that only status epilepticus stimulates the latent $\mathrm{KCl}$-activatable progenitor population. This result is consistent with the elevated levels of glutamate reported after status epilepticus (Meldrum, 1995), and the fact that prolonged incubation with high $\mathrm{KCl}$ was required to activate the precursors in vitro. Although we have used more extreme forms of activity (induction of epileptic seizures), our observations are consistent with previous reports of neural activity leading to increases in neurogenesis. It is well established that tasks involving learning and memory, as well as exercise, are capable of stimulating neurogenesis in the adult mouse hippocampus (van Praag et al., 1999) and such activity would be expected to raise extracellular $\mathrm{K}^{+}$.

In contrast to the hippocampus, the mechanisms of SVZ precursor regulation are quite different, because depolarization of cells from the SVZ led to a significant decrease in neurosphere numbers. Furthermore, blockade of L-type $\mathrm{Ca}^{2+}$ channels did not inhibit neurosphere formation in the SVZ in either the presence or absence of depolarizing levels of $\mathrm{KCl}$. These contrasting responses may explain why behavioral stimuli, such as environmental enrichment and running, are effective in increasing hippocampal neurogenesis (van Praag et al., 1999) but have little or no impact on neurogenesis in the SVZ (Brown et al., 2003). However, whether this regulation is at the level of the stem or progenitor cell remains unknown.

Our finding that depolarization activated only a small number (approximately eight) of normally latent stem cells capable of self-renewal and with high neurogenic potential may explain why previous studies, including our own (Seaberg and van der Kooy, 2002; Bull and Bartlett, 2005), failed to identify such a population. It also suggests that previous reports of self-renewing multipotent stem cells (Gage et al., 1995; Palmer et al., 1995, 1997) may be attributable to the environment provided by high-density monolayer adherent culture, which could support survival and eventual activation of this population. However, other highdensity monolayer cultures have not confirmed this finding (Seaberg and van der Kooy, 2002), raising the possibility of contamination by nonhippocampal progenitors. Our findings demonstrate an unequivocal way of differentiating hippocampal stem cells from those found in the SVZ, thereby providing a unique method to study their regulation, especially in regard to neurogenesis.

Stem cells have been identified in the early postnatal dentate gyrus but not in the adult hippocampus (Seaberg and van der Kooy, 2002). This posed the question as to the fate of these stem cells as the animals reach adulthood. Do they migrate away from the dentate gyrus or, alternatively, do they persist into adulthood but become quiescent? We showed that, although large numbers of multipotent neurospheres can be generated from the postnatal hippocampus, they are not responsive to additional KCl-induced stimulation. Why these cells are switched off in adulthood is unclear, but one possibility is that this corresponds to a time when growth of the hippocampus is complete (Sun et al. 2004), and continued neurogenesis is associated with functional replacement rather than new growth. This raises the interesting possibility that this latent population may have the capacity to generate other types of hippocampal neurons, or be more efficient at repairing the damaged hippocampus.

Consistent with recent findings that there is a substantial decrease in neurogenesis in the hippocampus with age (Seki and Arai, 1995; Kuhn et al., 1996), we find a concomitant decline in the progenitor population. However, even in mice 18 months of age, our results reveal a large population of activatable hippocampal progenitors, which may have the capacity to reverse the observed decline in neurogenesis. Whether these cells are partially responsible for the increase in neurogenesis and improved cognitive abilities that occur after running wheel exercise (van Praag et al., 1999) is not known, but they certainly provide a reservoir for the production of large numbers of neurons in the aging animal. However, from this perspective, it is somewhat salutatory to note that no large neurospheres were cultured from the aged hippocampus even in the presence of $\mathrm{KCl}$, suggesting that the stem cell population may be entirely depleted, somewhat restricting the propensity for ongoing progenitor replacement and neurogenesis. Nevertheless, given that there is only a small number of stem cells (approximately eight) in the young adult hippocampus, perhaps even less given that only one-third of these show convincing self-renewal capacity, it may be that this population is reduced to undetectable but still functionally significant levels. In addition, the finding that status epilepticus leads to a large increase in progenitor but not resident stem cell numbers in vitro indicates that the inability to detect these stem cells in the aged animal may be attributable to a loss of activation mechanisms rather than a loss of the stem cells per se. The identification of an activatable population of precursors provides a potential mechanism by which environmental inputs via synaptic activity may lead to large increases in neurogenesis and an expansion of neuronal numbers in the hippocampus. If this is true, discovering the underlying regulatory mechanism provides a target by which the production of new neurons could be stimulated to replace or repair damaged neurons in neurodegenerative diseases affecting the hippocampus, such as Huntington's disease, stroke, and aged dementia.

\section{References}

Altman J, Das GD (1965) Autoradiographic and histological evidence of postnatal hippocampal neurogenesis in rats. J Comp Neurol 124:319-335.

Arvidsson A, Kokaia Z, Airaksinen MS, Saarma M, Lindvall O (2001) Stroke induces widespread changes of gene expression for glial cell line-derived neurotrophic factor family receptors in the adult rat brain. Neuroscience 106:27-41.

Ballarin M, Ernfors P, Lindefors N, Persson H (1991) Hippocampal damage and kainic acid injection induce a rapid increase in RNA for BDNF and NGF in the rat brain. Exp Neurol 114:35-43.

Bendel O, Bueters T, von Euler M, Ove Ogren S, Sandin J, von Euler G (2005) Reappearance of hippocampal CA1 neurons after ischemia is associated with recovery of learning and memory. J Cereb Blood Flow Metab 25:1586-1595.

Brown J, Cooper-Kuhn CM, Kempermann G, van Praag H, Winkler J, Gage FH, Kuhn HG (2003) Enriched environment and physical activity stimulate hippocampal but not olfactory bulb neurogenesis. Eur J Neurosci 17:2042-2046.

Bull ND, Bartlett PF (2005) The adult mouse hippocampal progenitor is neurogenic but not a stem cell. J Neurosci 25:10815-10821.

Chen J, Park CS, Tang SJ (2006) Activity-dependent synaptic Wnt release regulates hippocampal long term potentiation. J Biol Chem 281:11910-11916. 
Deisseroth K, Singla S, Toda H, Monje M, Palmer TD, Malenka RC (2004) Excitation-neurogenesis coupling in adult neural stem/progenitor cells. Neuron 42:535-552.

Dolmetsch RE, Pajvani U, Fife K, Spotts JM, Greenberg ME (2001) Signalling to the nucleus by an L-type calcium channel-calmodulin complex through the MAP kinase pathway. Science 294:333-339.

Dugich-Djordjevic MM, Lapchak PA, Tocco G, Pasinetti G, Baudry M, Hefti F (1992) Regionally specific and rapid increases in BDNF mRNA in the adult rat brain following seizures induced by systemic administration of kainic acid. Neuroscience 47:303-315.

Ernfors P, Bengzon J, Kokaia Z, Persson H, Lindvall O (1991) Increased levels of messenger RNAs for neurotrophic factors in the brain during kindling epileptogenesis. Neuron 7:165-176.

Gage FH, Coates PW, Palmer TD, Kuhn HG, Fisher LJ, Suhonen JO, Peterson DA, Suhr ST, Ray J (1995) Survival and differentiation of adult neuronal progenitor cells transplanted to the adult brain. Proc Natl Acad Sci USA 92:11879-11883.

Goldman SA, Nottebohm F (1983) Neuronal production, migration, and differentiation in a vocal control nucleus of the adult female canary brain. Proc Natl Acad Sci USA 80:2390-2394.

Gould E, Beylin A, Tanapat P, Reeves A, Shors TJ (1999) Learning enhances adult neurogenesis in the hippocampal formation. Nat Neurosci 2:260-265.

Gould E, Tanapat P, Rydel T, Hastings N (2000) Regulation of hippocampal neurogenesis in adulthood. Biol Psychiatry 48:715-720.

Iacovitti L, Stull ND, Mishizen A (1999) Neurotransmitters, KCl and antioxidants rescue striatal neurons from apoptotic cell death in culture. Brain Res 816:276-285.

Isackson PJ, Huntsman MM, Murray KD, Gall CM (1991) BDNF mRNA expression is increased in adult rat forebrain after limbic seizures: temporal patterns of induction distinct from NGF. Neuron 6:937-948.

Jin K, Peel AL, Mao XO, Xie L, Cottrell BA, Henshall DC, Greenberg DA (2004) Increased hippocampal neurogenesis in Alzheimer's disease. Proc Natl Acad Sci USA 101:343-347.

Korte M, Carroll P, Wolf E, Brem G, Thoenen H, Bonhoeffer T (1995) Hippocampal long-term potentiation is impaired in mice lacking brainderived neurotrophic factor. Proc Natl Acad Sci USA 92:8856-8860.

Kuhn HG, Dickinson-Anson H, Gage FH (1996) Neurogenesis in the dentate gyrus of the adult rat: age-related decrease of neuronal progenitor proliferation. J Neurosci 16:2027-2033.

Lie DC, Colamarino SA, Song HJ, Désiré L, Mira H, Consiglio A, Lein ES, Jessberger S, Lansford H, Dearie AR, Gage FH (2005) Wnt signalling regulates adult hippocampal neurogenesis. Nature 437:1370-1375.

Liu J, Solway K, Messing RO, Sharp FR (1998) Increased neurogenesis in the dentate gyrus after transient global ischemia in gerbils. J Neurosci 18:7768-7778.

Lois C, Alvarez-Buylla A (1993) Proliferating subventricular zone cells in the adult mammalian forebrain can differentiate into neurons and glia. Proc Natl Acad Sci USA 90:2074-2077.

Luskin MB (1993) Restricted proliferation and migration of postnatally generated neurons derived from the forebrain subventricular zone. Neuron 11:173-189.

McEwen BS (1994) Corticosteroids and hippocampal plasticity. Ann NY Acad Sci 746:134-142.

Meldrum BS (1995) Excitatory amino acid receptors and their role in epilepsy and cerebral ischemia. Ann NY Acad Sci 757:492-505.
Nakatomi H, Kuriu T, Okabe S, Yamamoto S, Hatano O, Kawahara N, Tamura A, Kirino T, Nakafuku M (2002) Regeneration of hippocampal pyramidal neurons after ischemic brain injury by recruitment of endogenous neural progenitors. Cell 110:429-441.

Palmer TD, Ray J, Gage FH (1995) FGF-2-responsive neuronal progenitors reside in proliferative and quiescent regions of the adult rodent brain. $\mathrm{Mol}$ Cell Neurosci 6:474-486.

Palmer TD, Takahashi J, Gage FH (1997) The adult rat hippocampus contains primordial neural stem cells. Mol Cell Neurosci 8:389-404.

Parent JM, Yu TW, Leibowitz RT, Geschwind DH, Sloviter RS, Lowenstein DH (1997) Dentate granule cell neurogenesis is increased by seizures and contributes to aberrant network reorganization in the adult rat hippocampus. J Neurosci 17:3727-3738.

Ramirez-Amaya V, Marrone DF, Gage FH, Worley PF, Barnes CA (2006) Integration of new neurons into functional neural networks. J Neurosci 26:12237-12241.

Reynolds BA, Weiss S (1992) Generation of neurons and astrocytes from isolated cells of the adult mammalian central nervous system. Science 255:1707-1710.

Richards LJ, Kilpatrick TJ, Bartlett PF (1992) De novo generation of neuronal cells from the adult mouse brain. Proc Natl Acad Sci USA 89:8591-8595

Rietze RL, Valcanis H, Brooker GF, Thomas T, Voss AK, Bartlett PF (2001) Purification of a pluripotent neural stem cell from the adult mouse brain. Nature 412:736-739.

Santarelli L, Saxe M, Gross C, Surget A, Battaglia F, Dulawa S, Weisstaub N, Lee J, Durman R, Arancio O, Belzung C, Hen R (2003) Requirement of hippocampal neurogenesis for the behavioral effects of antidepressants Science 301:805-809.

Seaberg RM, van der Kooy D (2002) Adult rodent neurogenic regions: the ventricular subependyma contains neural stem cells, but the dentate gyrus contains restricted progenitors. J Neurosci 22:1784-1793.

Seki T, Arai Y (1995) Age-related production of new granule cells in the adult dentate gyrus. NeuroReport 6:2479-2482.

Shors TJ, Miesegaes G, Beylin A, Zhao M, Rydel T, Gould E (2001) Neurogenesis in the adult is involved in the formation of trace memories. Nature 410:372-376.

Sloviter RS (1983) Epileptic brain damage in rats induced by sustained electrical stimulation of the perforant path. I. Acute electrophysiological and light microscopic studies. Brain Res Bull 10:675-697.

Sun W, Winseck A, Vinsant S, Park O, Kim H, Oppenheim RW (2004) Programmed cell death of adult-generated hippocampal neurons is mediated by the proapoptotic gene Bax. J Neurosci 24:11205-11213.

van Praag H, Christie BR, Sejnowski TJ, Gage FH (1999) Running enhances neurogenesis, learning, and long-term potentiation in mice. Proc Natl Acad Sci USA 96:13427-13431.

Walker TL, Yasuda T, Adams DJ, Bartlett PF (2007) The doublecortinexpressing population in the developing and adult brain contains multipotential precursors in addition to neuronal-lineage cells. J Neurosci 27:3734-3742.

Xiu-Yu S, Ruo-Peng S, Ji-Wen W (2007) Consequences of pilocarpineinduced recurrent seizures in neonatal rats. Brain Dev 29:157-163.

Young KM, Merson TD, Sotthibundhu A, Coulson EJ, Bartlett PF (2007) p75 neurotrophin receptor expression defines a population of BDNFresponsive neurogenic precursor cells. J Neurosci 27:5146-5155. 